\title{
The Relationship Between Acidity and Short-Term Student Performance on Exams
}

\author{
Justin Raymond Croyle ${ }^{\mathrm{a}}$, Patricia Talarczyk ${ }^{\mathrm{a}}$
}

\begin{abstract}
All students have to take exams at some point in their schooling careers and often in overwhelming amounts. With tests carrying great importance, students try to optimize their performance on these tests in a variety of ways. A widely-practiced strategy is eating peppermint or candy during the test in hopes of boosting brain performance. Peppermint has been known to stimulate olfactory receptors in humans. Similarly, acidity is an alternative powerful taste stimulant. Although acidity stimulates taste receptors and not olfactory receptors, taste and smell are very closely related which makes peppermint and acidity have similar overall effects. Since peppermint has shown improved memory and cognition in students, this study will now examine how acidity effects brain performance. This inquiry was investigated by giving 84 local high school students beverages of ranging acidity levels and soon after having them complete a timed, four-function math exam to test their brain performance. With average test scores of $38.62,36.05$, and 40.02 for the highest acidity, medium acidity, and lowest acidity beverage respectively with a control (no drink) average of 39.33, acidity does not appear to have an effect on student brain stimulation ( $\mathrm{p}=.53)$. In conclusion, there was no statistically significant correlation between acidity and student brain function, but this was only a preliminary study and similar concepts should be further explored in the future.
\end{abstract}

Keywords: Acidity; Student Test Performance; Brain Stimulation

Testing is an integral part of students' lives whether for better or worse. Ranging from normal math tests to crucial standardized tests, pressure for students to perform well on exams is ever present. The point has been reached to where taking the SAT or ACT is virtually inevitable for most students seeking college degrees (Cavanagh, 2003). Students have to perform exceptionally in high school in order to have a chance of going to a prestigious university and potentially pursuing the career they so desperately want, prompting this pressure to perform well on exams.

The pressure on students to perform well fosters the use of many strategies that are integrated in efforts to improve students' cognition. These strategies can be long-term or short-term, ranging anywhere from getting a good night's sleep to eating peppermint or even chewing gum during an exam, as demonstrated by researchers at New York University (Allen, Norman, \& Katz, 2008). While some of these strategies are scientifically proven to be true, others still seem to be merely rumors and theories used by students and teachers in hopes of achieving that extra letter grade or percentile on a crucial standardized test. These short-term strategies are especially common as they are something quick and simple for students to use with seemingly no harm in doing so.

Some of these theories have been around for over a decade. To illustrate, researchers at the University of Northumbria, UK found that the aroma of peppermint generally improved students' memory and alertness during exams (Worth a Mint, 2008). Similarly, in 2007, a middle school principal decided to provide children peppermint candies to eat during an important week of standardized testing (Brand \& Ydstie, 2007). The principal also expressed uncertainty regarding whether or not the mints actually had any effect on the students.

Peppermint has a very distinct characteristic in that it has a powerful stimulation effect on one's senses, which could explain the effects of peppermint on students' brain function. Peppermint especially affects olfactory perception which can greatly affect planning and judgment in the brain (Sullivan, Warm, Schefft, Dember, O’Dell, \& Peterson, 1998). Another consumable that has a powerful stimulation effect is an acidic substance. However, taste receptors, and not olfactory receptors, are stimulated by the simple ions that compose acidic substances (Bradbury, 2004). Although being different senses, this similarity between peppermint and acidity of being impactful on human senses prompts the question of how acidity affects the brain and its functions since peppermint has already shown potential effects. When considering this topic, examining the current body of knowledge is integral to see what research has been conducted on acidity and its effects on the brain.

There are studies that have been conducted over the past few decades regarding similar correlations to acidity and its effects on brain function. Many studies looked into the effect of acidity on long-term human health. A specialist in water filtration discovered that acidity can have multiple effects on long-term human health including increased stress and more vulnerability to diseases (Goodkind, 2009). However, this is only after extensive consumption of acidic items as Goodkind noted in her study; consuming acidic foods or beverages just every so often would have little to no effect. Furthermore, other specific nutrients and foods have been proven to have the ability to improve brain function. In a scientific study, a UCLA Ph.D. researcher found that specific nutrients such as polyunsaturated fatty acids commonly found in many different types of berries have the ability to improve brain plasticity, memory function, and learning capabilities (Gómez-Pinilla, 2008). In the same vein, Julia Rucklidge and her colleagues found that a micronutrient composed of various vitamins and minerals improved multiple neurocognitive impairments that ADHD patients suffered from (Rucklidge, Harrison, \& Johnstone, 2011). Therefore, nutrients have been studied regarding their effects on brain function, but acidity has not. Although acidity is not a nutrient, no other taste sensations such as bitterness or sweetness have been studied in regards to brain performance. Additionally, many researchers have evaluated the best foods to consume immediately prior to an important exam. A standardized test preparation expert found that students that opt for energy drinks and sugars before an exam often fare significantly worse than students that eat other specific foods like whole-grain cereal, 
eggs, or toast (Carr, 2005). Therefore, there is research about specific foods that improve brain function for a test, but all of the qualities of these foods are not necessarily examined in depth with their specific effects on brain function. To reiterate, there have been many studies about the effects of acidity on long-term human health, specific nutrients that improve brain function, and certain food options that improve brain function during exams. From this information, a gap in the body of knowledge can be deduced. No studies consider the effects of acidic consumables on brain function during exams or tests. This prompts the question: how does the acidity of consumables affect students' short-term performance on timed mathematical assessments?

The primary focus of this paper is to determine if there is a correlation between the acidity of consumables and student performance on exams and to recommend the best options of consumables for students to eat or drink before an exam to ensure their brains are at peak performance. Students and schools are populations that could be greatly affected by the results of this inquiry and study. Outcomes of this study could have significant effects on student behavior and lifestyle. In an academic study, Texas A\&M researchers found that students who eat more home-cooked meals compared to fast food or other options can enhance student brain performance on exams (Green, 2010). This study could greatly affect student lifestyles by influencing students to cook more for themselves rather than buying premade meals. The researcher's study could also have a similar effect (depending on the results of the study) regarding the purchase of different consumables affecting students financially. This financial effect exhibits the vested interest of students in this study. Likewise, schools and administrations could be considerably affected by the results of this study. In Britain, some high school and college students were eating "brain foods" in efforts to perform better on their final exams which caused significantly increased sales in common superfoods like blueberries and bananas at local grocery stores (Students Eat Brain Food..., 2005). Since the local grocery stores reported more sales compared to usual, schools could then decide to carry these specific powerful consumables at their cafeterias and make a substantial amount of money because students would buy these items. This not only prompts economic effects for schools but can also improve the rating of the school if the "brain foods" actually do help students improve their test scores. Therefore, schools would have a high vested interest in this study.

Another notable aspect of this study is the chemistry and principles behind the effects of acidity. Acidity is a quality of a substance that is measured using a pH scale which assigns numbers to substances from zero to fourteen. Zero to seven is considered acidic and seven to fourteen is basic with an exact $\mathrm{pH}$ of seven being completely neutral. Common examples of acidic consumables include citrus and coffee while common examples of slightly basic consumables include broccoli and avocado according to an expert dietician (Goodkind, 2009). The safe consumable range for humans is generally accepted to be between two and nine on the $\mathrm{pH}$ scale. Scientifically, $\mathrm{pH}$ is the relative concentrations of hydrogen ions to hydroxide ions. More hydrogen ions correlate to a more acidic substance and more hydroxide ions correlate to a more basic substance (Norden, 2003). Consequently, more hydrogen ions correspond to a more sour substance and more hydroxide ions correspond to a more bitter substance as common acids are sour and common bases are bitter. Another important scientific principle to note is that taste and smell are closely related. According to a Ph.D. graduate, smell and taste are closely related because as a person consumes and tastes something, the scent molecules drift up into the nasal cavity and stimulate the olfactory receptors which commonly makes the brain combine the taste and smell sensations as one (Cowart, 2009). Thus, the effect that acidity may or may not have on brain function could come from the smell or taste of the acidic consumables.

As aforementioned, there have been many studies over the past few decades discussing the effects of acidity on human health and specific foods or nutrients on brain performance. However, there have been no studies that analyze the effects of acidity on student brain performance. This study will research the effects of the acidity of a consumable on student brain performance on a timed mathematical exam. This study is important because it can have immensely positive effects for not only students but als o schools and administrators. Even though there are no other similar studies, increased acidity can be hypothesized to improve brain performance because acidity can have a stimulating effect like peppermint which has been shown to increase brain function for students.

\section{Method}

The method that was used to collect the data for this study was a quasi-experimental method in which the independent variable was manipulated. In this study, participants consumed different beverages of different acidity levels and then proceeded to take a timed, four-function math test to display their brain function after consuming the beverage. A quantitative quasi-experimental method was chosen because there was a clear and numeric independent variable (the $\mathrm{pH}$ of the beverage) that could be tested on a clear and numeric dependent variable (the score of the timed, four-function math test). This method was quasi-experimental because ensuring a completely random experiment was nearly impossible especially considering the scope and feasibility of this study. Beverages were chosen as the acidic medium compared to foods because beverages have much fewer total ingredients. This is more ideal because extra ingredients increase the chance of creating an unwanted variable; therefore, beverages were chosen over foods to limit specific ingredients from potentially skewing the results. Math tests were also specifically chosen because the arithmetic on the exam used is a very common practice used in schools. Furthermore, this specific method was chosen because many other similar studies also utilized comparable methods. For example, in a similar academic study where brain training was being tested on its effects on brain function, the researchers used an experimental method in which participants received different levels of brain training and were then tested on their brain function using an exam (Owen et al., 2010). Since similar studies in the body of knowledge used experimental methods and collected clear results, an experimental method was determined to also be the most optimal method for this study.

Moreover, this study had four different groups to ensure the clearest results possible. There was a bottled regular water group, a bottled lemon water group, a local tap water group, and a no-drink group. The tap water group was specifically created as a control for hydration itself having an impact on brain performance. According to a study from the Emory University Research Committee, hydration alone can have significant impacts on cognition and alertness (Chard, Trinies, Edmonds, Sogore, \& Freeman 
2019). Therefore, the tap water group was absolutely necessary to control for the effects of hydration itself on brain function since this study is aimed at determining the effects of the acidity of the beverage on brain function. Then, the no-drink group was created as a standard control for the effects of beverage acidity. Finally, there was the bottled regular water group and the bottled lemon water group. Both of these beverages are on the acidic range of the $\mathrm{pH}$ scale with the bottled lemon water being more acidic than the bottled regular water. The exact pHs are 3.03, 5.03, and 7.15 for the bottled lemon water, bottled regular water, and tap water respectively. These values are represented in Figure 1 . These beverages specifically were chosen in part because of the relatively constant interval of about two $\mathrm{pH}$ units between them. The bottled regular water is still slightly acidic due to the way it is packaged and purified using carbon dioxide. To ensure that different manufacturing processes did not affect the results, the bottled lemon water and bottled regular water were both from the same national brand. The decision was made to have a weak version and then a stronger version of the independent variable (slightly acidic and moderately acidic) because other similar studies showed that this strategy yielded clearer results and trends in the data. The aforementioned researchers from the Nature Publishing Group also used two levels of experimental groups so that trends could more easily be correlated (Owen et al., 2010). Therefore, this study also used two levels of experimental groups: the bottled regular water group and the bottled lemon water group along with the controls for hydration (tap water group) and acidity (no-drink group).

Figure 1. $\mathrm{pH}$ of Beverages

8

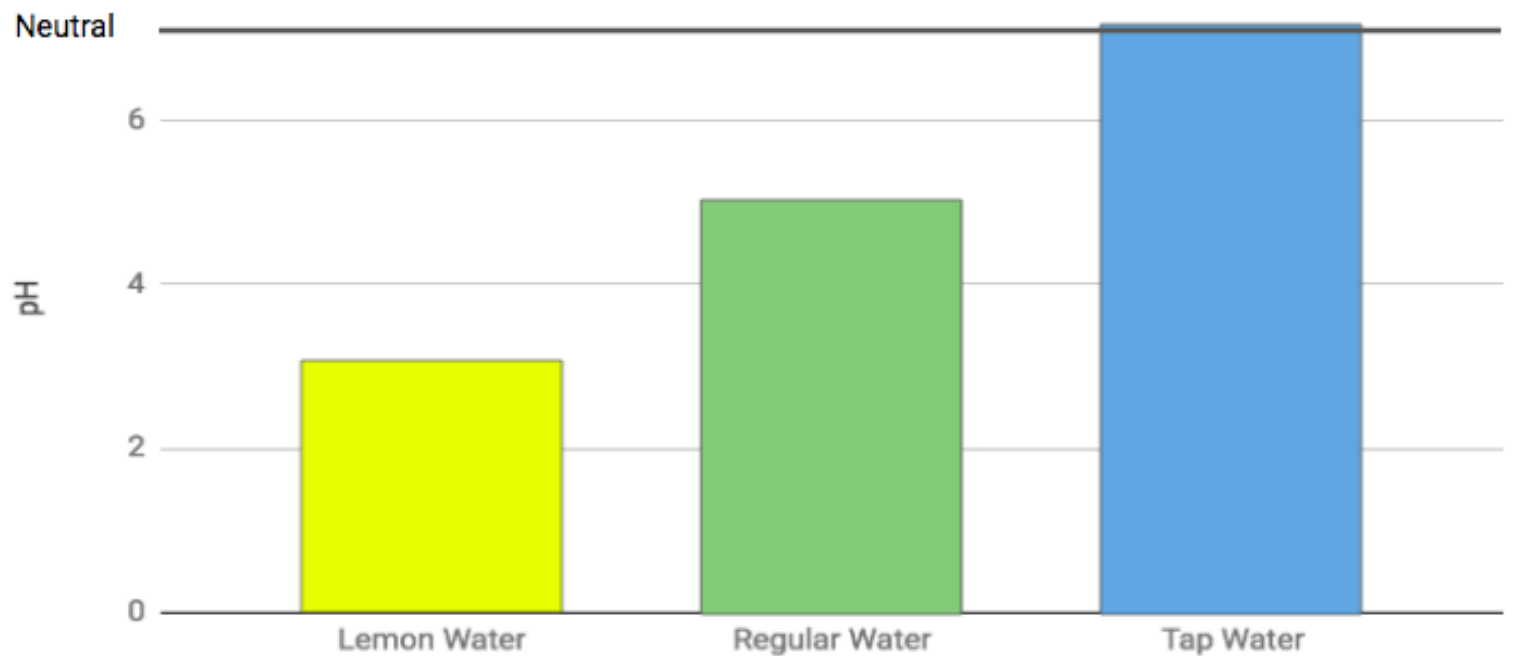

Figure 1. The $\mathrm{pH}$ for bottled lemon water and bottled regular water were determined from reputable scientists and the $\mathrm{pH}$ of the local tap water was determined by the student researcher using a digital $\mathrm{pH}$ meter. The student researcher also recorded comparable values for bottled lemon and bottled regular water to those of the scientists (Reddy, Norris, Momeni, Waldo, \& Ruby, 2016).

The design for this experimental method was for participants to drink a beverage of varying acidity (or no beverage as in the no-drink group), wait for everyone to finish drinking, and then take the timed, four-function math test with one hundred questions with numbers one to twelve in any combination. This exam was procedurally generated from the website "webmathminute.com" and was kept constant for all participants (Web Math Minute, 2018). The specific amount of beverage that was consumed by each participant was kept exactly the same and the time between when the students finished the beverage and began the test was also controlled. Likewise, the amount of time given to complete the test was controlled. All participants were also taking very similar math courses limited to AP Calculus BC, AP Calculus AB, and Pre-Calculus Honors. For this reason, a paired t-test was not used in this study because the participants were all very similar in mathematical ability so no compensation for the difference in skill of the participants was taken. This also made finding participants more feasible because they only had to commit to one session and not multiple sessions with the paired t-test option. 
The implementation of this study was rather quick and direct in efforts to limit the time needed from the participants. First, the researcher gathered plastic, disposable cups and all of the different types of beverages. Then, the cups were labeled for different beverages. The researcher used "X" for bottled lemon water, "Y" for bottled regular water and " $Z$ " for the tap water. All of the cups were then filled with the same amount of beverage being two-thirds of a cup. On the day of the study, the participants were first given the assent form which, if completed, warranted their participation in the study. After this, the cups were passed out systematically; the researcher went through each teacher's seating chart and distributed the drinks in a pattern (lemon, regular, tap, and no drink). Next, the researcher distributed the exams face-down. Then, the participants were asked to drink the beverage (or no beverage in the no-drink group) and had exactly one minute to do so. Then, the participants were given one minute to complete as much of the test as possible. To clarify, the drinking minute and the testing minute were completely separate. After time was up, the participants were asked to stop all work and flip their test over again to fill out some secondary data along with their beverage letter, current math course, teacher, and class period (the test given is shown in Appendix A and the other questions including secondary data questions are shown in Appendix B). Finally, the researcher collected and disposed of all of the cups and collected the exams from the participants. At a later date, the researcher graded the exams according to a strict premade answer key to eliminate any potential bias. Any uncompleted problems were marked as wrong in the grading process (the premade key to the exam is shown in Appendix C).

The participants of this study were chosen by convenience sample. All of the participants are students at a local high school that are currently enrolled in either AP Calculus BC, AP Calculus AB, or Pre-Calculus Honors as aforementioned. The use of math classes was integral to this study because the test used to examine brain function and performance consisted of only mathematical questions. For this reason, ensuring that the students were at similar levels of math ability was key for this study. Advanced Placement and honors classes specifically were chosen because the researcher wanted to ensure the participants took the exam seriously to limit skewed results. All participants remained in their normal school seating chart so that they remained comfortable for the exam, therefore limiting the variable of comfortability. As stated previously, each student filled out an assent form that declared their willingness to participate in the study. The assent form made clear that everything would remain completely anonymous and that all participation was absolutely voluntary, thus giving participants the right to withdraw from the study at any time. Furthermore, all risks, although minimal, were outlined in the assent form. These minor risks included potentially consuming a disliked beverage and experiencing slight stress due to taking a timed exam. Finally, this entire study was fully approved by a local institutional review board before implementation, further guaranteeing that this study was conducted ethically and with the participants' safety in mind.

\section{Results}

Table 1.

Beverage and Test Scores

\begin{tabular}{lll}
\hline Beverage & Mean & Standard Deviation \\
\hline Bottled Lemon Water & 38.62 & 8.92 \\
Bottled Regular Water & 36.05 & 9.05 \\
Tap Water & 40.52 & 11.00 \\
No Drink & 39.33 & 11.24 \\
\hline Total & 38.63 & 10.06 \\
\hline
\end{tabular}

In order to perform a proper analysis of the data collected, the raw data must be presented first. The raw results of this study demonstrate that the tap water group actually had the highest mean score on the test followed closely by the no-drink group participants and then the bottled lemon water participants. However, there was a larger gap between the bottled lemon water and bottled regular water participants. This data can be seen in Table 1. Table 1 illustrates the mean scores of each treatment group: bottled lemon water, bottled regular water, tap water, and no-drink. The standard deviations of each treatment group are also represented in Table 1. The mean score represents the average number out of one hundred that students received on the timed, fourfunction math test. To clarify, wrong answers and unanswered problems were not counted; only correct answers were counted towards the score being worth one point each. Table 1 initially demonstrates no trend with the average test score decreasing and then increasing with an overall decreasing acidity level of the beverage. 
Table 2.

Beverage Rating and Test Scores

\begin{tabular}{lll}
\hline Beverage Rating & Mean & Standard Deviation \\
\hline Like & 38.63 & 8.75 \\
Indifferent & 37.46 & 10.60 \\
Dislike & 39.75 & 10.61 \\
\hline Total & 38.40 & 9.72 \\
\hline
\end{tabular}

Table 2 represents the mean scores and standard deviations based on beverage rating. Additionally, Table 3 shows the mean scores and standard deviations based on the math course. Table 2, similar to Table 1, does not appear to illustrate a trend in the data with the mean test score decreasing and then increasing with an overall decrease in participant satisfaction of the beverage. However, Table 3 does exhibit a slight correlation as the average test scores decreased accordingly with decreasing difficulty of the currently enrolled math course of the participants. The participants were permitted to complete the exam however they wanted to; for example, participants were allowed to skip questions or go in unconventional orders. The participants were comprised of 43 females and 41 males. Of those participants, 44 were currently enrolled in AP Calculus AB, 21 were currently enrolled in AP Calculus BC, and 19 were currently enrolled in Pre-Calculus Honors. All of the participants were from the same local, public high school. A statistical test will be used to analyze and see if these differences in scores are statistically significant or not.

Table 3.

Current Math Course and Test Scores

\begin{tabular}{lll}
\hline Current Math Course & Mean & Standard Deviation \\
\hline AP Calculus BC & 41.67 & 9.56 \\
AP Calculus AB & 38.30 & 10.24 \\
Pre-Calculus Honors & 36.05 & 9.83 \\
\hline Total & 38.63 & 10.06 \\
\hline
\end{tabular}

Table 4.

Analysis

ANOVA Output per Trait

\begin{tabular}{lcc}
\hline Trait & f-ratio & p-value \\
\hline Beverage Acidity & 0.74 & .53 \\
Beverage Rating & 0.23 & .80 \\
Current Math Course & 1.63 & .20 \\
\hline
\end{tabular}

To analyze statistical significance in the data, a one-way ANOVA test was used. This test was completed using the website "socscistatistics.com" (Social Science Statistics, 2019). This was determined to be a reliable source and was primarily used to limit possible human error in the calculations. All outputs from the ANOVAs are demonstrated in Table 4. The first ANOVA was performed with the beverage acidity being the variable on the test scores. The mean test scores were 38.62, 36.05, 40.52, and 39.33 for bottled lemon water, bottled regular water, tap water, and no-drink groups respectively. This data shows that there was no correlation with acidity and student brain performance because the highest acidity yielded a mean test score higher than the medium acidity beverage but lower than both the neutral beverage and no-drink group. There would have been a trend if bottled lemon water, bottled regular water, and tap water had increasing or decreasing mean scores in that order, but this did not occur since the score decreased from bottled lemon to bottled regular water, but then increased from bottled regular water to tap water with an overall decrease in acidity of the beverage. In addition, with a range of only 4.47 between the mean test scores for each tre atment group, beverage acidity does not appear to affect student brain performance on timed math exams. This is further supported by the 
high p-value of .53 consequently showing that the data is not statistically significant at a .10 confidence level. The .10 confidence level was chosen because of the rather limited scope of this study being only participants in a select few math courses from the same local, public high school. Therefore, the hypothesis that increasing acidity would improve brain performance for students on math exams should be rejected.

Additionally, another ANOVA was performed to find the beverage ratings' effect on the test scores. This data was insignificant at a 10 confidence level with a p-value of .80. One final ANOVA was performed on the currently enrolled math courses' effect on the test scores. This data was also statistically insignificant at a .10 confidence level with a p-value of .20. Although insignificant, this data was the closest to obtaining significance out of the results of this study. With the effect of the currently enrolled math course being close to statistically significant, there is a slight chance that this did actually play a role in how well the students performed on the tests. As seen in the results, the highest mean score for that ANOVA was 41.67 for AP Calculus BC, followed by 38.30 for AP Calculus AB, and 36.05 for Pre-Calculus Honors. Since the averages decreased with a decrease in the difficulty of the math course, the currently enrolled math course did seem to have a slight overall effect on the participants' test scores which is important because the slight difference of math courses was originally determined to be irrelevant.

Therefore, one limitation of this study was having to get participants from different math courses because this did have an impact on the data overall. Having participants from only one math course would have limited the data being skewed as a result of different mathematical ability because every participant would have been from the same course likewise having the same or very similar mathematical ability compared to this study. As stated in the results, students were permitted to skip questions and go in any order they chose on the exam. A t-test statistical analysis was used to analyze if people who skipped questions performed differently than those who did not. A two-tailed t-test was used because there were two groups of people: those who skipped and those who did not skip, and there could have been an effect in either improving or worsening scores for the students and not just one or the other. In fact, the statistical analysis showed that students who skipped questions actually scored worse on the test which is supported by a p-value of .05. This is likely because students who skipped questions did so because they did not know some of the answers to the questions. Not knowing answers quickly would naturally lead to a lower score because no participant fully completed the test, so not knowing answers quickly severely lowers the test score. This shows that students who skipped questions did not gain any advantages as a result of this technique compared to others and therefore did not skew the data. Even though people who skipped problems performed worse, the variable of skipping was still not determined to have skewed the data because skipping was a result of people not knowing answers quickly and not an independent variable in and of itself. However, not doing a pretest-posttest method definitely limited the study. The range of all test scores was 48 with the highest being only 65 . With this very large range, some participants seemed to naturally perform well on this test compared to others who naturally performed poorly on this test because of their initial abilities. With these exams not being commonplace in high school, the skills needed to perform well on this exam were niche, which opened the way for some to perform very well and others to perform very poorly on this exam without an effect from a variable. Accordingly, a pretest-posttest method should have been utilized to account for the specific skills required by these types of exams so that one's original ability did not affect the outcome of the study. This method would have eliminated any possibility that the data was affected just by the initial skill of the participants; however, this method was not feasible due to the amount of extra time required. Additionally, this study was limited to math tests thus leaving a chance for acidity to still affect student performance on other subjects like English and language arts. Due to the limited scope of this study, only one type of exam could be used. Finally, this study was limited to only one high school in northeast Ohio leaving the potential for other schools and other geographical areas to have different results.

\section{Conclusion}

Despite statistically insignificant results, there are still numerous implications of this study. The results showed that beverage acidity did not have any effect on student brain performance, which indicates that students do not need to drink beverages that are more acidic than others in order to perform better on school exams. Furthermore, the results indicate that students' beverage preferences do not affect their performance. This means that if there is some other quality that affects brain performance, but students do not enjoy those drinks, they should still consider consuming those beverages because students' beverage preferences do not affect their performance. The results of this study also have implications for the current body of knowledge. Researchers like Sullivan and his colleagues proved that peppermint did improve cognition and memory. They may now, as a result of this study, want to further dive into the science behind peppermint to see why it has this cognitive benefit because the results of this study showed that this benefit was not caused by a stimulation effect. Likewise, the school that gave their students peppermint would want to ensure that if they give students something before exams, the item remains to be peppermint. This is because other things that have stimulating effects, like acidity, did not have the same effect, thus ruling out candies as an actual benefit to students as well. Also, since beverage rating did not have an effect on test performance, then test-prep diets from Carr's article should be catered less with what the student enjoys and more to healthy and energy-providing foods and beverages. Students should consider a nutrient-packed breakfast rather than a flavorful one.

However, further research should certainly be done in other areas with larger populations and sample sizes to confirm the outcomes of this research since there were multiple limitations of this study. In addition, there are no studies comparing acidity to student brain performance in the current body of knowledge further warranting the need for future research to not only confirm the results of this study but also to explore and test other similar variables that this study did not examine. For example, further research could be done to see if acidity affects student brain performance on tests relating to other subjects. This study only considered math exams, but English, language arts, science, and social studies exams could all potentially yield different results. Moreover, this study only tested acidic substances, but perhaps basic substances could have an effect on brain performance because they are commonly bitter. Another option would be to test if the acidity of food affects performance and also how other qualities and 
nutrients in beverages or food affects brain performance. Connecting back to Sullivan, more research should be done to see what component or characteristic of peppermint causes the increased brain performance he found. This could potentially be done by isolating the individual components of peppermint to see the specific part that causes improvements in brain performance so that this component can be applied to other consumables. This topic of inquiry is new and not yet fully developed leaving a wide gap for future research. In conclusion, this study can only be considered as a preliminary study of this topic of inquiry because of the constraints and limitations encountered making future research of this topic absolutely necessary. Nonetheless, despite other studies finding peppermint to improve memory and cognition, the results of this study illustrate that beverage acidity does not affect student brain performance on math exams. However, this study lays the foundation for the gap in the current research that can continue to be built upon in the future.

\section{References}

Allen, K. L., Norman, R. G., \& Katz, R. V. (2008). The Effect of Chewing Gum on Learning as Measured by Test Performance. Nutrition Bulletin, 33(2), 102-107.

Bradbury, J. (2004). Taste Perception: Cracking the Code. PLoS Biology, 2(3), 295-297.

Brand, M. \& Ydstie, J. (2007). School Back Peppermint for Student Alertness. National Public Radio.

Carr, C. (2005). Test-Prep Diet. Time, 165(14), W7.

Cavanagh, S. (2003). More Take College-Entrance Exams; Academic Readiness Is Questioned. Education Week, 23(1), 13.

Chard, A. N., Trinies, V., Edmonds, C. J., Sogore, A., \& Freeman, M. C. (2019). The Impact of Water Consumption on Hydration and Cognition Among Schoolchildren: Methods and Results from a Crossover Trial in Rural Mali. PLoS ONE, 14(1), 1-14.

Cowart, B. (2009). Smell and Taste: Close Relations. Consumer Reports on Health, 21(1), 7.

Gómez-Pinilla, F. (2008). Brain Foods: The Effects of Nutrients on Brain Function. Nature Reviews. Neuroscience, 9(7), 568-578.

Goodkind, R. (2009). The Multiple Benefits of A Balanced Ph. LILIPOH, 14(57), 62-65.

Green, R. J. (2010). Brain Food: The Relationship Between Home-Cooked Meals and Student Success. College Student Journal, 44(3), 720.

Norden, R. L. (2003). Do You Really Know What pH Is? Journal of Environmental Health, $65(6), 48$.

Owen, A. M., Hampshire, A., Grahn, J. A., Stenton, R., Dajani, S., Burns, A. S., ... Ballard, C. G. (2010). Putting Brain Training to the Test. Nature, 465(7299), 775.

Reddy, A., Norris, D. F., Momeni, S. S., Waldo, B., \& Ruby, J. D. (2016). The pH of Beverages in the United States. American Dental Association.

Rucklidge, J. J., Harrison, R., \& Johnstone, J. (2011). Can Micronutrients Improve Neurocognitive Functioning in Adults with ADHD and Severe Mood Dysregulation? A Pilot Study. Journal of Alternative \& Complementary Medicine, 17(12), 1125-1131.

Social Science Statistics. (March 4, 2019). Retrieved from https://www.socscistatistics.com/Default.aspx

Students Eat Brain Food Before Exams. (2005). UPI NewsTrack (Consumer Health).

Sullivan, T. E., Warm, J. S., Schefft, B. K., Dember, W. N., O’Dell, M. W., \& Peterson, S. J. (1998). Effects of Olfactory Stimulation on the Vigilance Performance of Individuals with Brain Injury. Journal Of Clinical And Experimental Neuropsychology, 20(2), 227-236.

Web Math Minute. (November 2, 2018). Retrieved from https://webmathminute.com/ Worth a Mint. (2008). American Herb Association Quarterly Newsletter, 23(2), 12. 


\begin{tabular}{|c|c|c|c|c|c|c|c|c|c|}
\hline $\begin{array}{r}2 \\
\times \quad 3 \\
\end{array}$ & $\begin{array}{r}9 \\
-\quad 4 \\
\end{array}$ & $\begin{array}{r}1 \\
\times \quad 4 \\
\end{array}$ & $\begin{array}{r}8 \\
+\quad 1 \\
\end{array}$ & $\begin{array}{r}9 \\
\times \quad 5 \\
\end{array}$ & $\begin{array}{r}12 \\
-\quad 11 \\
\end{array}$ & $\begin{array}{r}11 \\
\times \quad 3 \\
\end{array}$ & $\begin{array}{r}1 \\
\times \quad 1 \\
\end{array}$ & $\begin{array}{r}7 \\
\times \quad 11 \\
\end{array}$ & $\begin{array}{r}7 \\
+\quad 9 \\
\end{array}$ \\
\hline $\begin{array}{r}11 \\
-\quad 9 \\
\end{array}$ & $\begin{array}{r}4 \\
\times \quad 7 \\
\end{array}$ & $\begin{array}{r}70 \\
\div \quad 7 \\
\end{array}$ & $\begin{array}{r}18 \\
\div \quad 3 \\
\end{array}$ & $\begin{array}{r}11 \\
-\quad 7 \\
\end{array}$ & $\begin{array}{r}3 \\
+\quad 11 \\
\end{array}$ & $\begin{array}{r}9 \\
-\quad 6 \\
\end{array}$ & $\begin{array}{r}10 \\
-\quad 1 \\
\end{array}$ & $\begin{array}{r}8 \\
+\quad 5 \\
\end{array}$ & $\begin{array}{r}55 \\
\div \quad 11 \\
\end{array}$ \\
\hline $\begin{array}{r}40 \\
\div \quad 8 \\
\end{array}$ & $\begin{array}{r}11 \\
-\quad 9 \\
\end{array}$ & $\begin{array}{r}24 \\
\div \quad 8 \\
\end{array}$ & $\begin{array}{r}2 \\
+\quad 2 \\
\end{array}$ & $\begin{array}{r}1 \\
+\quad 9 \\
\end{array}$ & $\begin{array}{r}44 \\
\div \quad 11 \\
\end{array}$ & $\begin{array}{r}5 \\
\times \quad 4 \\
\end{array}$ & $\begin{array}{r}10 \\
-\quad 5 \\
\end{array}$ & $\begin{array}{r}2 \\
\times \quad 1 \\
\end{array}$ & $\begin{array}{r}5 \\
\times \quad 5 \\
\end{array}$ \\
\hline $\begin{array}{r}4 \\
+\quad 10 \\
\end{array}$ & $\begin{array}{r}2 \\
+\quad 6 \\
\end{array}$ & $\begin{array}{r}6 \\
\times \quad 9 \\
\end{array}$ & $\begin{array}{r}60 \\
\div \quad 10 \\
\end{array}$ & $\begin{array}{r}7 \\
\times \quad 10 \\
\end{array}$ & $\begin{array}{r}7 \\
-\quad 1 \\
\end{array}$ & $\begin{array}{r}6 \\
\times \quad 6 \\
\end{array}$ & $\begin{array}{r}2 \\
+\quad 4 \\
\end{array}$ & $\begin{array}{r}6 \\
+\quad 6 \\
\end{array}$ & $\begin{array}{r}10 \\
-\quad 3 \\
\end{array}$ \\
\hline $\begin{array}{r}11 \\
+\quad 2 \\
\end{array}$ & $\begin{array}{r}1 \\
\times \quad 4 \\
\end{array}$ & $\begin{array}{r}9 \\
-\quad 2 \\
\end{array}$ & $\begin{array}{r}11 \\
+\quad 2 \\
\end{array}$ & $\begin{array}{r}81 \\
\div \quad 9 \\
\end{array}$ & $\begin{array}{r}3 \\
+\quad 3 \\
\end{array}$ & $\begin{array}{r}8 \\
\times \quad 9 \\
\end{array}$ & $\begin{array}{r}40 \\
\div \quad 10 \\
\end{array}$ & $\begin{array}{r}5 \\
+\quad 4 \\
\end{array}$ & $\begin{array}{r}6 \\
+\quad 7 \\
\end{array}$ \\
\hline $\begin{array}{r}12 \\
+\quad 5 \\
\end{array}$ & $\begin{array}{r}5 \\
-\quad 2 \\
\end{array}$ & $\begin{array}{r}10 \\
+\quad 7 \\
\end{array}$ & $\begin{array}{r}5 \\
-\quad 3 \\
\end{array}$ & $\begin{array}{r}4 \\
+\quad 1 \\
\end{array}$ & $\begin{array}{r}4 \\
-\quad 4 \\
\end{array}$ & $\begin{array}{r}44 \\
\div \quad 11 \\
\end{array}$ & $\begin{array}{r}33 \\
+\quad 3 \\
\end{array}$ & $\begin{array}{r}8 \\
+\quad 7 \\
\end{array}$ & $\begin{array}{r}11 \\
\times \quad 1\end{array}$ \\
\hline $\begin{array}{r}12 \\
\div \quad 1 \\
\end{array}$ & $\begin{array}{r}2 \\
-\quad 2 \\
\end{array}$ & $\begin{array}{r}84 \\
\div \quad 12 \\
\end{array}$ & $\begin{array}{r}9 \\
+\quad 2 \\
\end{array}$ & $\begin{array}{r}6 \\
-\quad 1 \\
\end{array}$ & $\begin{array}{r}2 \\
\times 10 \\
\end{array}$ & $\begin{array}{r}5 \\
-\quad 2 \\
\end{array}$ & $\begin{array}{r}5 \\
\times \quad 12 \\
\end{array}$ & $\begin{array}{r}2 \\
+\quad 8 \\
\end{array}$ & $\begin{array}{r}6 \\
-\quad 3 \\
\end{array}$ \\
\hline $\begin{array}{r}9 \\
-\quad 6 \\
\end{array}$ & $\begin{array}{r}8 \\
-\quad 7 \\
\end{array}$ & $\begin{array}{r}12 \\
-\quad 2 \\
\end{array}$ & $\begin{array}{r}9 \\
\times \quad 11 \\
\end{array}$ & $\begin{array}{r}12 \\
+\quad 12 \\
\end{array}$ & $\begin{array}{r}3 \\
\div \quad 1 \\
\end{array}$ & $\begin{array}{r}60 \\
\div \quad 6 \\
\end{array}$ & $\begin{array}{r}40 \\
\div \quad 10 \\
\end{array}$ & $\begin{array}{r}12 \\
\times \quad 12 \\
\end{array}$ & $\begin{array}{r}2 \\
+\quad 2 \\
\end{array}$ \\
\hline $\begin{array}{r}11 \\
-\quad 6 \\
\end{array}$ & $\begin{array}{r}60 \\
\div \quad 6 \\
\end{array}$ & $\begin{array}{r}3 \\
+\quad 5 \\
\end{array}$ & $\begin{array}{r}16 \\
\div \quad 2 \\
\end{array}$ & $\begin{array}{r}3 \\
\div \quad 1 \\
\end{array}$ & $\begin{array}{r}16 \\
\div \quad 4 \\
\end{array}$ & $\begin{array}{r}2 \\
-\quad 2 \\
\end{array}$ & $\begin{array}{r}1 \\
+\quad 5 \\
\end{array}$ & $\begin{array}{r}12 \\
+\quad 4 \\
\end{array}$ & $\begin{array}{r}6 \\
-\quad 6 \\
\end{array}$ \\
\hline $\begin{array}{r}6 \\
+\quad 12 \\
\end{array}$ & $\begin{array}{r}11 \\
\times \quad 9 \\
\end{array}$ & $\begin{array}{r}121 \\
\div \quad 11 \\
\end{array}$ & $\begin{array}{r}1 \\
+\quad 7 \\
\end{array}$ & $\begin{array}{r}12 \\
+\quad 10 \\
\end{array}$ & $\begin{array}{r}12 \\
\times \quad 1 \\
\end{array}$ & $\begin{array}{r}11 \\
\times \quad 2 \\
\end{array}$ & $\begin{array}{r}5 \\
+\quad 3 \\
\end{array}$ & $\begin{array}{r}7 \\
-\quad 3 \\
\end{array}$ & $\begin{array}{r}81 \\
\div \quad 9\end{array}$ \\
\hline
\end{tabular}


Appendix B

Beverage Letter:

Gender:

Current Grade Level:

Math Teacher and Mods:

Currently Enrolled Math Course:

Beverage Rating (Circle One):

Like

Indifferent

Dislike 


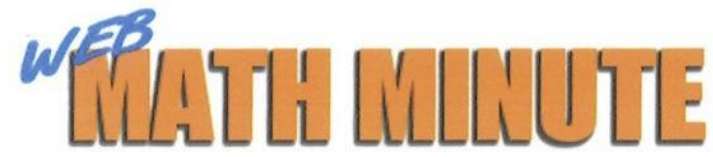

\begin{tabular}{|rrrrrrrrrr}
\hline \multicolumn{1}{|c|}{ Answers for Sheet\# 2345-01 } \\
6 & 5 & 4 & 9 & 45 & 1 & 33 & 1 & 77 & 16 \\
2 & 28 & 10 & 6 & 4 & 14 & 3 & 9 & 13 & 5 \\
5 & 2 & 3 & 4 & 10 & 4 & 20 & 5 & 2 & 25 \\
14 & 8 & 54 & 6 & 70 & 6 & 36 & 6 & 12 & 7 \\
13 & 4 & 7 & 13 & 9 & 6 & 72 & 4 & 9 & 13 \\
17 & 3 & 17 & 2 & 5 & 0 & 4 & 11 & 15 & 11 \\
12 & 0 & 7 & 11 & 5 & 20 & 3 & 60 & 10 & 3 \\
3 & 1 & 10 & 99 & 24 & 3 & 10 & 4 & 144 & 4 \\
5 & 10 & 8 & 8 & 3 & 4 & 0 & 6 & 16 & 0 \\
18 & 99 & 11 & 8 & 22 & 12 & 22 & 8 & 4 & 9
\end{tabular}

